\section{Identification of three novel frameshift mutations in patients with Friedreich's ataxia}

EDITOR-Friedreich's ataxia (FRDA, MIM 229300) is an autosomal recessive, progressive, neurodegenerative disorder. It is the most common of all hereditary ataxias, with an estimated prevalence of 1 in 50000 , and a carrier frequency calculated to be as high as 1 in 90 in white populations. Onset normally occurs between 8 and 15 years of age, presenting as ataxia of gait accompanied by dysarthria, areflexia, extensor plantar responses, and distal loss of position and vibration sense. The involvement of other systems is also apparent, and in particular most patients die prematurely from hypertrophic cardiomyopathy.

The FRDA gene encodes a highly conserved protein, designated frataxin, which localises to the mitochondrial matrix and appears to be involved in the efflux of iron from mitochondria. ${ }^{1-4}$ Patients with FRDA have reduced levels of frataxin expression, which probably leads to mitochondrial iron accumulation and free radical damage of oxidative phosphorylation processes..$^{5-8}$ The predominant mutation, accounting for approximately $98 \%$ of FRDA chromosomes, is expansion of a GAA trinucleotide repeat located within intron 1 of the FRDA gene. ${ }^{19}$ Normal subjects have 6-36 GAA repeats at this position, whereas FRDA patients have expansions of $120-1700$ repeats..$^{10-12}$ The GAA expansion has been postulated to interfere with frataxin transcription by forming a triple helical based "sticky DNA" structure. ${ }^{13}{ }^{14}$ An estimated $96 \%$ of FRDA patients are homozygous for the GAA expansion and a correlation between severity of the disease phenotype and the size of the smaller of the two alleles has been identified. ${ }^{2}$ The remaining $4 \%$ of FRDA patients are compound heterozygotes, having a GAA expansion at one allele and either a known point mutation $(2.5 \%)$ or an as yet unidentified mutation $(1.5 \%)$ at the other allele. ${ }^{9}$ No instance of an FRDA patient carrying two frataxin point mutations has yet been described, and thus it is possible that complete frataxin loss may be lethal.

To date there have been 20 different FRDA point mutations reported (table 1), comprising single base pair deletions (two cases), insertions (one case), and substitutions (eight cases of transitions and nine of transversions). Ten of these point mutations are predicted to produce truncated or absent frataxin protein and, in general, these mutations are positioned within the 5 ' region of the FRDA gene. In contrast, 10 missense mutations have been identified primarily in the highly conserved regions of exons 3, 4, and $5 \mathrm{a}$. We report here the identification of three novel $F R D A$ mutations that all result in frameshifts of the frataxin coding sequence. This includes the detection of a mutation hot spot in exon 3, the first description of a mutation in exon 2 , and the first identification of point mutations that involve more than a single base pair rearrangement.

Investigation for mutation at the FRDA locus was undertaken in patients exhibiting early onset Friedreich's ataxia from three unrelated families to confirm diagnosis. Patient 1 is a 7 year old male, who presented initially at the age of $31 / 2$ years with poor balance and coordination. $\mathrm{He}$ now exhibits areflexia and impaired joint position sense. Right sural and digital sensory nerve action potentials are absent and median combined action potential is significantly diminished. ECG is normal. Patient 2 is a severely affected 14 year old male who presented at the age of 3 years and was wheelchair bound by 10 years. An echocardiogram shows cardiomyopathy. Patient 3 is a 16 year old male who presented at the age of 3 years with a rapidly progressing ataxia. He became wheelchair bound at the age of 12 years and underwent vertebral fusion to correct his scoliosis at the age of 14 years. He now shows cardiac involvement.

Genomic DNA was isolated from whole blood using standard procedures. Repeat expansions were detected by PCR amplification of 250 ng DNA using primers GAA-F and GAA-R ${ }^{1}$ together with the Expand ${ }^{\mathrm{TM}}$ long template PCR system (Boehringer Mannheim, Lewes, UK) under

Table 1 Frataxin mutations

\begin{tabular}{|c|c|c|c|c|}
\hline Location & Mutation & Nucleotide change & Effect & Reference \\
\hline \multirow[t]{5}{*}{ Exon 1} & $1 \mathrm{~A} \rightarrow \mathrm{C}$ & $\mathrm{A} \rightarrow \mathrm{C}$ at 1 & Incorrect initiation & 9 \\
\hline & $2 \mathrm{~T} \rightarrow \mathrm{C}$ & $\mathrm{T} \rightarrow \mathrm{C}$ at 2 & Incorrect initiation & 9 \\
\hline & $3 \mathrm{G} \rightarrow \mathrm{T}$ & $\mathrm{G} \rightarrow \mathrm{T}$ at 3 & Incorrect initiation & $18,22,23$ \\
\hline & 157delC $\dagger$ & Deletion of C at 157 & Frameshift & 9 \\
\hline & 157 ins $\mathrm{C}+$ & Insertion of $\mathrm{C}$ after 157 & Frameshift & 9 \\
\hline Exon 2 & 202GTCA $\rightarrow$ TTG & GTCA $\rightarrow$ TTG at 202-205 & Frameshift & * \\
\hline \multirow[t]{5}{*}{ Exon 3} & L106X & $\mathrm{T} \rightarrow \mathrm{G}$ at 317 & Nonsense & 1 \\
\hline & L106S & $\mathrm{T} \rightarrow \mathrm{C}$ at 317 & Missense & 17 \\
\hline & 317delT & Deletion of $T$ at 317 & Frameshift & $\star$ \\
\hline & 340del13 & Deletion of $13 b p$ between 340 and 352 & Frameshift & * \\
\hline & $\mathrm{D} 122 \mathrm{Y}$ & $\mathrm{G} \rightarrow \mathrm{T}$ at 364 & Missense & 9 \\
\hline \multirow[t]{2}{*}{ Intron 3} & IVS3 $+1 \mathrm{G} \rightarrow \mathrm{A}$ & $\mathrm{G} \rightarrow \mathrm{A}$ at $384+1$ & Splice mutation & 24 \\
\hline & IVS3 $-2 \mathrm{~A} \rightarrow \mathrm{G}$ & $A \rightarrow G$ at $385-2$ & Splice mutation & 1 \\
\hline \multirow[t]{3}{*}{ Exon 4} & G130V & $\mathrm{G} \rightarrow \mathrm{T}$ at 389 & Missense & 9,16 \\
\hline & $\mathrm{I} 154 \mathrm{~F}$ & $\mathrm{~A} \rightarrow \mathrm{T}$ at 460 & Missense & 1,11 \\
\hline & L156P & $\mathrm{T} \rightarrow \mathrm{C}$ at 467 & Missense & 9 \\
\hline \multirow[t]{2}{*}{ Intron 4} & IVS $4+2 \mathrm{~T} \rightarrow \mathrm{G}$ & $\mathrm{T} \rightarrow \mathrm{G}$ at $482+2$ & Splice mutation & 19 \\
\hline & IVS4+3delA & Deletion of A at $482+3$ & Splice mutation & 9 \\
\hline \multirow[t]{5}{*}{ Exon $5 a$} & R165C & $\mathrm{C} \rightarrow \mathrm{T}$ at 493 & Missense & 19 \\
\hline & W173G & $\mathrm{T} \rightarrow \mathrm{G}$ at 517 & Missense & 9 \\
\hline & L182F & $\mathrm{C} \rightarrow \mathrm{T}$ at 544 & Missense & 19 \\
\hline & $\mathrm{L} 182 \mathrm{H}$ & $\mathrm{T} \rightarrow \mathrm{A}$ at 545 & Missense & 9 \\
\hline & H183R & $\mathrm{A} \rightarrow \mathrm{G}$ at 548 & Missense & 9 \\
\hline
\end{tabular}

*The three novel frameshift mutations described in this study are indicated in bold type.

$\nmid 157 \mathrm{delC}$ and 157 ins $\mathrm{C}$ were originally designated $158 \mathrm{delC}$ and 158 ins $\mathrm{C}$, respectively. ${ }^{9}$ 


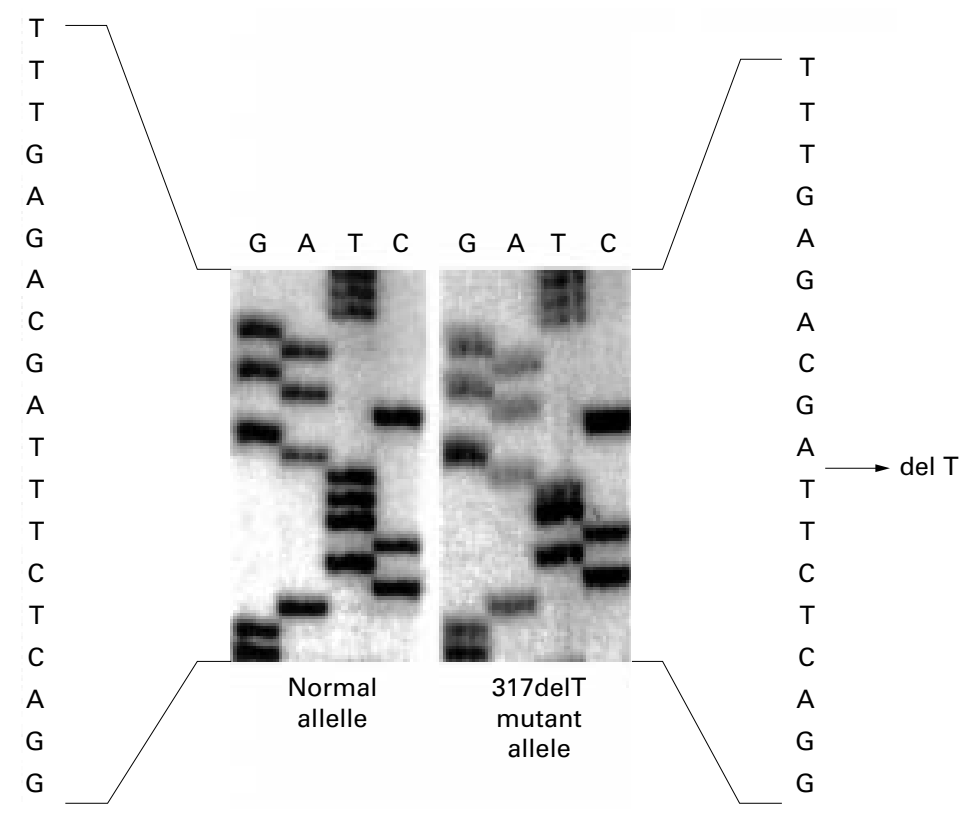

Figure 1 Sequence identification of the frataxin 317 delT mutation. Sequence analysis of two cloned frataxin exon 3 PCR products from patient 1 's amplified genomic DNA showing both normal and 317 delT mutant alleles. Frataxin exon 3 sequence is indicated by upper case letters. The deletion of a $T$ at position 317 is indicated by an arrow.

conditions recommended by the manufacturer. PCR products were resolved on $2 \%$ agarose gels, Southern blotted onto Hybond $\mathrm{N}^{+}$membrane, and hybridised with a $\gamma^{32} \mathrm{P}$ end labelled (GAA) $)_{10}$ oligonucleotide in Church buffer at $55^{\circ} \mathrm{C}$. After washing to $0.1 \times \mathrm{SSC}, 0.1 \% \mathrm{SDS}$ at $55^{\circ} \mathrm{C}$, positively hybridising bands were visualised by exposure to $x$ ray film and sized. SSCP and heteroduplex analysis was performed on PCR amplified products corresponding to frataxin exons 1 to $5 \mathrm{~b}$ and encompassing the respective exon-intron boundaries, using intronic primer pairs ${ }^{1}$ and conditions as previously described..$^{15}$ DNA sequencing was performed on both strands of PCR products that were either agarose gel purified, excised from SSCP bands and reamplified, or T cloned into pCR2.1 (Invitrogen, Groningen, Holland) using either $\left[\alpha-{ }^{33} \mathrm{P}\right]$ dATP with a T7 sequencing kit (Amersham Pharmacia, Amersham, UK) or ABI310A/ABI Prism 377 DNA sequencers (Applied Biosystems Inc, Foster City, CA). DdeI restriction enzyme digestion of frataxin exon 3 PCR amplified products was carried out according to conditions recommended by the manufacturer, and digested samples were electrophoresed on a $2 \%$ agarose gel.

As a result of diagnostic screening for FRDA we identified three subjects from unrelated families who showed heterozygosity for the GAA expansion. All three patients had an early onset, a typical to more severe FRDA phenotype, and their GAA expansion sizes were approximately 500, 1000, and 1050 repeats, respectively. Systematic screening of all frataxin exons, including exon-intron boundaries, was therefore undertaken in order to identify the putative second mutation. This consisted of an initial resolution of exonic PCR products on 3\% Nusieve agarose gels, followed by SSCP/heteroduplex analysis, and subsequent direct sequencing.

In all three cases mutations involving microdeletions of frataxin coding sequence were identified (table 1), with resultant frameshifts and the predicted use of premature stop codons to produce a truncated frataxin protein. The mutation in patient 1 was detected as an exon 3 band shift by heteroduplex analysis, and subsequent sequencing showed this to be a single base deletion, 317 delT, in a run of three Ts (fig 1). This 317 delT mutation generates an immediate premature stop codon at amino acid position 106, essentially mimicking the previously reported L106X mutation. ${ }^{1}$ The mutation in patient 2 was detected as an exon 2 band shift by SSCP analysis, and sequencing of the reamplified excised band showed this to be a complex substitution mutation in which the GTCA sequence at position $202 / 205$ has been replaced by TTG (fig 2). The origin of this unusual 202GTCA $\rightarrow$ TTG mutation is unknown, but functionally it would be expected to act like a single base deletion, establishing a frameshift and subsequent premature stop codon at nucleotide positions 224-226 in exon 2 . The mutation in patient 3 was initially identified by agarose gel analysis as an additional smaller than normal exon 3 PCR fragment. Upon sequencing of the PCR product, this mutation was shown to be a $13 \mathrm{bp}$ deletion of exon 3 coding sequence, 340del13 (fig 3), which generates a frameshift and premature stop codon at nucleotide positions 395-397 in exon 4.

The occurrence of the novel frameshift mutations in other available family members and normal subjects was then examined. The 317 delT mutation was found to establish a novel $D d e I$ restriction enzyme site in frataxin exon 3, giving rise to a convenient PCR product digestion screening method. Using this method, maternal transmission of the 317 delT mutated allele to patient 1 was detected (fig 4). No mutation was found in 200 normal chromosomes. Direct DNA sequencing of frataxin exon 3 also showed that the $13 \mathrm{bp}$ deletion mutation (340del13) was present in an affected sib of patient 3 .

The identification of three novel microdeletion mutations of the frataxin gene now adds to the growing list of point mutations to be found in FRDA compound heterozygotes (table 1). The mutations, designated 202 GTCA $\rightarrow$ TTG, 317delT, and 340del13, each result in a frameshift and have predicted premature stop codons in frataxin exons 2, 3, and 4, respectively. Two other frameshift mutations, $157 \mathrm{delC}$ and $157 \mathrm{insC}$, have previously been reported, ${ }^{9}$ having similar predicted premature stop codons in exons 2 and 3. Other types of mutations that are expected to result in a truncated or absent frataxin 


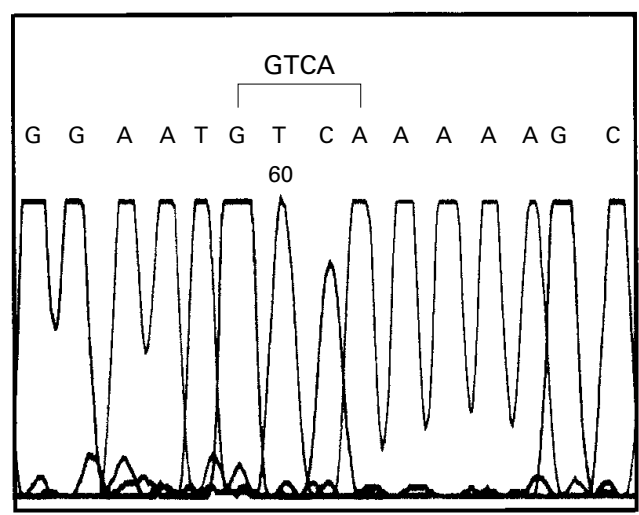

Normal

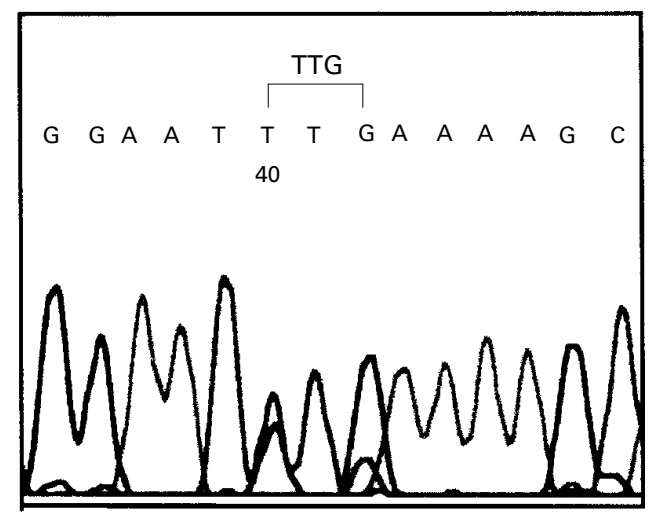

202GTCA $\longrightarrow$ TTG

Figure 2 Sequence identification of the frataxin 202GTCA $\rightarrow$ TTG mutation. Direct sequence of exon 2 PCR products in (1) a normal subject and (2) patient 2, showing substitution of GTCA for TTG at nucleotide position 202. The exon 2 $P C R$ product of patient 2 was derived by reamplification of a gel extracted SSCP shifted band which has resulted in amplification of some background wild type sequence as well.

protein have also been identified, including incorrect initiation codon sequences, a nonsense mutation, and splice site mutations (table 1). Such truncating mutations, including the three reported here, are generally clustered towards the $5^{\prime}$ end of the frataxin gene. Thus, they are expected to produce non-functional truncated frataxin molecules that lack highly conserved domains found in exons 3 to $5 \mathrm{a} .{ }^{1}$ The effect of this on the compound heterozygotes may be an overall tendency towards a more severe disease phenotype. Indeed, the three patients described here, who have GAA expansions of 500, 1000, and 1050 repeats, all presented with a very early age at onset.

The genotype-phenotype correlation of frataxin missense mutations is less predictable, depending on whether the mutation results in a conservative or non-conservative amino acid change and whether it is in a functionally important domain or not. Most of the missense mutations that have been identified so far are non-conservative changes in highly conserved regions, ${ }^{9}$ resulting in nonfunctional frataxin and a typical to severe FRDA phenotype, as seen in the patients with truncating mutations. However, three missense mutations in the less highly conserved regions of frataxin (L106S, D122Y, and G130V) have been reported in mildly affected FRDA patients. ${ }^{9}{ }^{16} 17$

Some individual FRDA point mutations (M1I, G130V, $\mathrm{I} 154 \mathrm{~F}$, and $\mathrm{W} 173 \mathrm{G}$ ) have been found in several unrelated families, highlighting the functional importance of particular frataxin amino acid residues. ${ }^{9}{ }^{18} 19$ In addition, different point mutations that cause alteration of the same amino acid residue have also been identified, such as the three
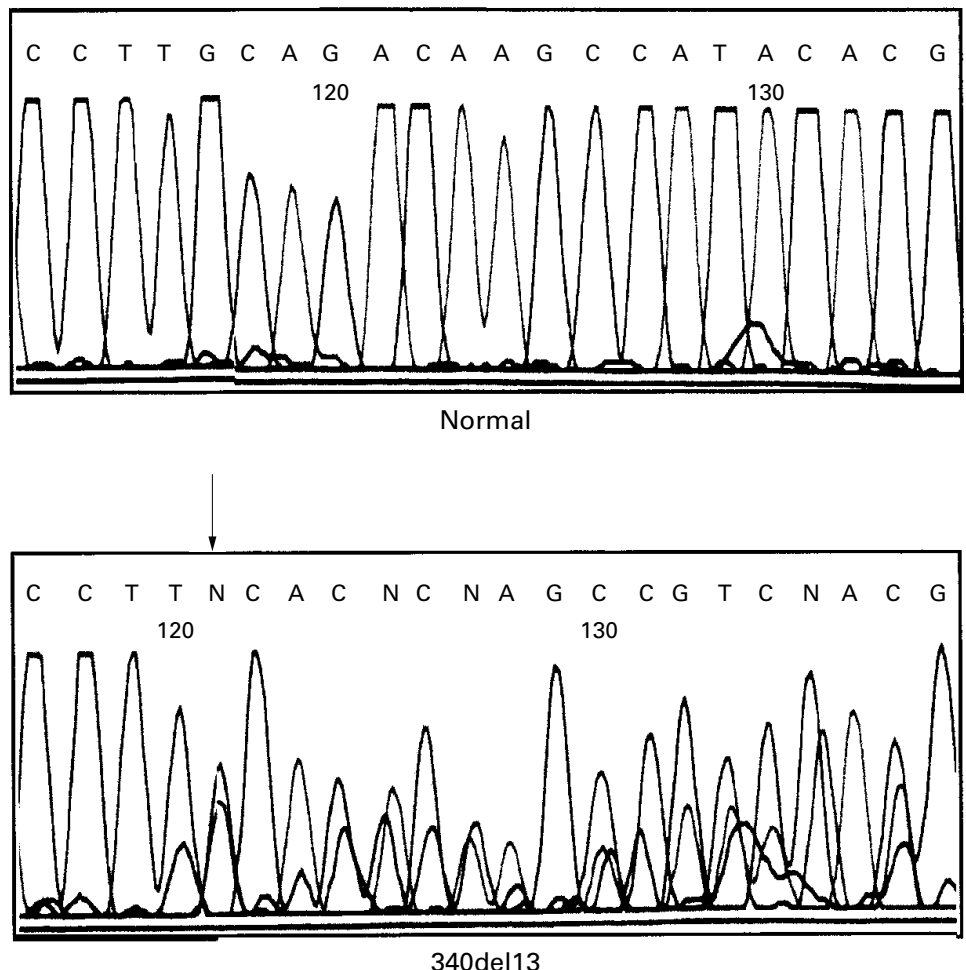

Figure 3 Sequence identification of the frataxin 340 del13 mutation. Direct sequence of exon 3 PCR products in (1) a normal subject and (2) patient 3, showing a 13 bp deletion beginning at nucleotide position 340. An arrow indicates the frameshift at position 340 where normal and mutant alleles begin to overlap. 

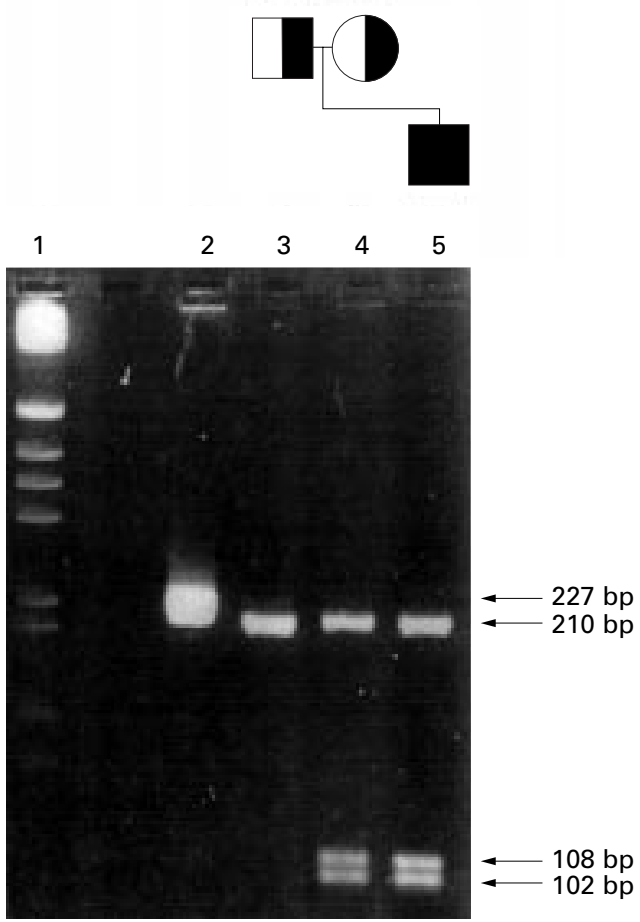

Figure 4 Detection of the 317 delT mutation by DdeI digestion. DdeI digests of frataxin exon 3 PCR products run on a $2 \%$ agarose gel showing detection of the 317 delT mutation. The normal $227 \mathrm{bp}$ exon 3 PCR product cuts once with DdeI to give fragments of $210 \mathrm{bp}$ and $17 \mathrm{bp}$ (not shown). The 317 delT mutation introduces a second DdeI site further cleaving the $210 \mathrm{bp}$ into fragments of $108 \mathrm{bp}$ and $102 \mathrm{bp}$. Lane 1:1 kb ladder (Gibco BRL, Paisley, UK). Lane 2: uncut exon 3 PCR product. Lanes 3-5: DdeI digested PCR products with the corresponding family pedigree shown above. Lane 3: father of patient 1. Lane 4: mother of patient 1. Lane 5: patient 1. Arrows indicate an uncut 227 bp product, a normal $210 \mathrm{bp}$ DdeI fragment, and a doublet (108 bp and $102 \mathrm{bp}$ ) representing the mutant allele.

initiation codon mutations $1 \mathrm{~A} \rightarrow \mathrm{C}, 2 \mathrm{~T} \rightarrow \mathrm{C}$, and $3 \mathrm{G} \rightarrow \mathrm{T}$. ${ }^{9}$ Conversely, clustering of mutations at specific regions of the frataxin gene may indicate susceptibility of the sequence to mutational change, rather than functional consequence. In this respect, it is interesting to note that the 137 delT mutation identified in this study is now the third mutation to involve a rearrangement of the nucleotide at position 137, the other two mutations being a $\mathrm{T} \rightarrow \mathrm{G}$ transversion $(\mathrm{L} 106 \mathrm{X})^{1}$ and a $\mathrm{T} \rightarrow \mathrm{C}$ transition (L106S). ${ }^{17}$ Therefore, frataxin nucleotide position 137 may be regarded as a hot spot of mutation. Hot spots of DNA damage often originate in methylated $\mathrm{CpG}$ sequences owing to spontaneous deamination of 5-methyl cytosine $(5-\mathrm{mC})$ to thymine,${ }^{20}$ or in short repeat sequences owing to slipped strand mispairing. ${ }^{21}$ However, in the case of frataxin position 137 there is no apparent predisposing sequence, other than a short run of three Ts that may be involved in initiating the $137 \mathrm{delT}$ mutation. From a functional view, the $137 \mathrm{delT}$ and L106X mutations are expected to produce the same species of truncated frataxin protein and may give rise to a similar disease phenotype, depending on the size of the GAA expansion in the second allele. Thus, although still of a young age, patient 1 who harbours the 137 delT mutation and a 500 GAA repeat expansion already has signs of severe FRDA disease, resembling that of the two French patients who have the L106X mutation and GAA repeat sizes of 700 and 733, respectively. ${ }^{9}$

The other two frameshift mutations described in this study, 202GTCA $\rightarrow$ TTG and 340del13, add a further complexity to both the positioning and the type of frataxin mutations identified so far. 202GTCA $\rightarrow$ TTG is the first mutation to be identified in exon 2 of the frataxin gene, and thereby shows that there is now at least one mutation in each of the five main frataxin exons. Only the intron 2 region and the 5 ' and 3 ' control regions of the frataxin gene now remain without a reported FRDA mutation (table 1). In addition, 202GTCA $\rightarrow$ TTG and 340 del 13 are the first complex point mutations to be reported in FRDA patients. Although the frequency of compound heterozygous FRDA patients is low, frataxin point mutation identification and analysis is of immediate relevance to the prognosis in each individual family and is more generally beneficial in establishing genotype-phenotype correlations and understanding the mechanism of FRDA pathogenesis.

This work was supported by grants from ATAXIA and The Wellcome Trust. MARK A POOK* SAHAR A H AL-MAHDAWI* NEIL H THOMAS† RICHARD APPLETON ANDREW NORMANS ROGER MOUNTFORD SUSAN CHAMBERLAIN*

${ }^{\star}$ Hereditary Ataxia Research Group, Department of Molecular Genetics, Division of Biomedical Sciences, Sir Alexander Fleming Building, Imperial College School of Science Technology and Medicine, Exhibition Road, London SW7 2AZ, UK

†Paediatric Neurology, Child Health, Southampton General Hospital, Southampton, UK

$\ddagger$ Paediatric Neurology, Alder Hey Children’s Hospital, Liverpool, UK \Clinical Genetics, Birmingham Women's Hospital, Birmingham, UK qMolecular Genetics Laboratory, Liverpool Women's Hospital, Liverpool, $U K$

Correspondence to: Dr Pook, m.pook@ic.ac.uk

1 Campuzano V, Montermini L, Molto MD, Pianese L, Cossee M, Cavalcanti F, Monros E, Rodius F, Duclos F, Monticelli A, Zara F, Canizares J, Koutnikova H, Bidichandani SI, Gellera C, Brice A, Trouillas P, De Michele G, Filla A, De Frutos R, Palau F, Patel PI, Di Donato S, Mandel JL, Cocozza S, Koenig M, Pandolfo M. Friedreich's ataxia: autosomal recessive disease caused by an intronic GAA triplet repeat expansion. Science 1996; 271:1423-7.

2 Campuzano V, Montermini L, Lutz Y, Cova L, Hindelang C, Jiralerspong S, Trottier Y, Kish SJ, Faucheux B, Trouillas P, Authier FJ, Durr A, Mandel JL, Vescovi A, Pandolfo M, Koenig M. Frataxin is reduced in Friedreich ataxia patients and is associated with mitochondrial membranes. Hum Mol ataxia patients and is as
Genet 1997;6:1771-80.

3 Koutnikova H, Campuzano V, Foury F, Dolle P, Cazzalini O, Koenig M. Studies of human, mouse and yeast homologues indicate a mitochondrial Studies of human, mouse and yeast homologue

4 Radisky DC, Babcock MC, Kaplan J. The yeast frataxin homologue mediates mitochondrial iron efflux. Evidence for a mitochondrial iron cycle. $\mathcal{F}$ Biol Chem 1999;274:4497-9.

5 Rotig A, de Lonlay P, Chretien D, Foury F, Koenig M, Sidi D, Munnich A, Rustin P. Aconitase and mitochondrial iron-sulphur protein deficiency in Friedreich ataxia. Nat Genet 1997;17:215-17.

6 Wilson RB, Roof DM. Respiratory deficiency due to loss of mitochondrial DNA in yeast lacking the frataxin homologue. Nat Genet 1997;16: 352-7

7 Babcock M, de Silva D, Oaks R, Davis-Kaplan S, Jiralerspong S, Montermini L, Pandolfo M, Kaplan J. Regulation of mitochondrial iron accumulation by Yfh1p, a putative homolog of frataxin. Science 1997;276: 1709-12.

8 Wong A, Yang J, Cavadini P, Gellera C, Lonnerda B, Taroni F, Cortopassi G. The Friedreich's ataxia mutation confers cellular sensitivity to oxidant stress which is rescued by chelators of iron and calcium and inhibitors of stress which is rescued by chelators of iron
apoptosis. Hum Mol Genet 1999;8:425-30.

9 Cossee M, Durr A, Schmitt M, Dahl N, Trouillas P, Alinson P, Kostrzewa M, Nivelon-Chevallier A, Gustavson KH, Kohlschutter A, Muller U, ManM, Nivelon-Chevallier A, Gustavson KH, Kohlschutter A, Muller U, Man-
del J-L, Brice A, Koenig M, Cavalcanti F, Tammaro A, De Michele G, Filla A, Cocozza S, Labuda M, Montermini L, Poirier J, Pandolfo M. Friedreich's ataxia: point mutations and clinical presentation of compound heterozygotes. Ann Neurol 1999;45:200-6.

10 Durr A, Cossee M, Agid Y, Campuzano V, Mignard C, Penet C, Mandel JL, Brice A, Koenig M. Clinical and genetic abnormalities in patients with Friedreich's ataxia. N Engl f Med 1996;335:1169-75.

11 Filla A, De Michele G, Cavalcanti F, Pianese L, Monticelli A, Campanella G, Cocozza S. The relationship between trinucleotide (GAA) repeat length and clinical features in Friedreich ataxia. Am F Hum Genet 1996;59: 554-60.

12 Montermini L, Andermann E, Labuda M, Richter A, Pandolfo M, Cavalcanti F, Pianese L, Iodice L, Farina G, Monticelli A, Turano M, Filla A, De Michele G, Cocozza S. The Friedreich ataxia GAA triplet repeat: A, De Michele G, Cocozza S. The Friedreich ataxia GAA trip

13 Ohshima K, Montermini L, Wells RD, Pandolfo M. Inhibitory effects of expanded GAA.TTC triplet repeats from intron I of the Friedreich ataxia gene on transcription and replication in vivo. $\mathcal{F}$ Biol Chem 1998;273:1458895 . 
14 Sakamoto N, Chastain PD, Parniewski P, Ohshima K, Pandolfo M, Griffith JD, Wells RD. Sticky DNA: self-association properties of long GAA.TTC repeats in R.R.Y triplex structures from Friedreich's ataxia. Mol Cell 1999; 3:465-75

15 Carvajal JJ, Pook MA, Doudney K, Hillerman R, Wilkes D, Al-Mahdawi S, Williamson R, Chamberlain S. Friedreich's ataxia: a defect in signal transduction? Hum Mol Genet 1995;4:1411-19.

16 Bidichandani SI, Ashizawa T, Patel PI. Atypical Friedreich ataxia caused by compound heterozygosity for a novel missense mutation and the GAA triplet-repeat expansion. Am f Hum Genet 1997;60:1251-6.

17 Bartolo C, Mendell JR, Prior TW. Identification of a missense mutation in a Friedreich's ataxia patient: implications for diagnosis and carrier studies. Am ₹ Med Genet 1998;79:396-9.

18 Zuhlke C, Laccone F, Cossee M, Kohlschutter A, Koenig M, Schinger E. Mutation of the start codon in the FRDAl gene: linkage analysis of three pedigrees with the ATG to ATT transversion points to a unique common ancestor. Hum Genet 1998;103:102-5.
19 Forrest SM, Knight M, Delatycki MB, Paris D, Williamson R, King J, Yeung L, Nassif N, Nicholson GA. The correlation of clinical phenotype in FrieA The correlation of clinical phenotypo gene. Neurogenetics 1998;1:253-7.

20 Denissenko MF, Chen JX, Tang MS, Pfeifer GP. Cytosine methylation determines hot spots of DNA damage in the human P53 gene. Proc Natl Acad Sci USA 1997;94:3893-8.

21 Darvasi A, Kerem B. Deletion and insertion mutations in short tandem repeats in the coding regions of human genes. Eur F Hum Genet 1995;3:14-20.

22 Cossee M, Campuzano V, Koutnikova H, Fischbeck K, Mandel JL, Koenig M, Bidichandani SI, Patel PI, Molte MD, Canizares J, De Frutos R, Pianese L, Cavalcanti F, Monticelli A, Cocozza S, Montermini L, Pandolfo M. Frataxin fracas. Nat Genet 1997;15:337-8.

23 Laccone A, Schloesser M. A novel point mutation Met1Ile in the X25 gene responsible for Freidreich's ataxia. Hum Mutat 1997;11:415.

24 Doudney K, Pook M, Al-Mahdawi S, Carvajal J, Hillerman R, Chamberlain S. A novel splice site mutation (384+1G-A) in the Friedreich's ataxia gene. Hum Mutat 1997;11:415. 